\title{
IbM PEMANFAATAN ENCENG GONDOK DAN JERAMI SEBAGAI PAKAN TERNAK DAN PUPUK ALTERNATIF DI DESA NGARGOREJO
}

\author{
Suryono \\ Fakultas Pertanian, Universitas Sebelas Maret Surakarta \\ email: suryono_uns@yahoo.com
}

\begin{abstract}
Science and technology for society program (IbM) on Ngargorejo Village. The usage of Water Hyacinth (Euchornia crassipes) and Straw as an Cattle Feed and Fertilizer Alternative in cooperation with two partners, namely : Mina Sejahtera Breeders Group and Ngudi Makmur Farmers Group Association subdistrict Ngargorejo Ngemplak Boyolali with the distance of about $20 \mathrm{~km}$ from UNS . Problems experienced by Mina Sejahtera Breeders Group can be identified as follows : the presence of water hyacinth disrupt fish farms as waters cover, water hyacinth removed only inside of reservoir and allowed to sit there. Problems experienced Gapoktan Ngudi Makmur is the availability of fertilizer is still highly dependent on chemical fertilizers manufactured, so greatly disrupt the smooth process of agricultural production and the price of chemical fertilizers manufactured, so unstable / erratic even tend to be expensive, which is ultimately detrimental to the farmers. The solutions offered to solve the problems that arise is to identify problems than continued training and practice composting of water hyacinth and straw as fertilizer and cattle feed. Outcomes that would result from the IbM action plan that will include a scientific article published by the journal in the University of Sebelas March and models / tools appropriate technology ( TTG) in the form of trash thrasher, that partners used to make compost. As a result of this activities, training making cattle feed and fertilizer from water hyacinth and straw have been carried out. The delivery of aid water hyacinth and straw thrasher, and continued to the practice of making fertilizer and cattle feed from water hyacinth and straw.
\end{abstract}

Keywords: fertilizers, cattle feed, water hyacinth, straw

\section{PENDAHULUAN}

Akhir-akhir ini dunia kepariwisataaan cenderung berkembang kearah tumbuhnya spesifikasi minat wisatawan terhadap macam perjalanan atau jenis wisata yang dilakukan. Diantaranya adalah wisata alam (ekowisata) yang mengedepankan daya tarik alam (naturebased tourism).

Penyelenggaraan kepariwisataan merupakan perangkat yang sangat penting dalam pegembangan ekonomi suatu daerah. Pengembangan sektor pariwisata merupakan bagian kegiatan ekonomi yang multi dimensional yang tidak hanya mempunyai tujuan akhir berupa output ekonomi tetapi juga menyangkut masalah social, agama, budaya dan keamanan yang bahkan menjadi ruh pariwisata untuk dieksploitasi menjadi daya tarik wisata yang mempunyai daya jual tinggi
Kabupaten Boyolali memiliki luas wilayah $1.015,10 \mathrm{~km}^{2}$ yang membentang dari barat ke timur sepanjang $49 \mathrm{~km}$ dan dari utara ke selatan sekitar $54 \mathrm{~km}$. Di sebelah utara berbatasan dengan Kabupaten Grobogan, disebelah timur dengan Kabupaten Sragen, Kabupaten Karanganyar dan Kota Surakarta. Sebelah selatan dengan Kabupaten Klaten sedangkan di sebelah barat dengan Kabupaten Semarang dan Kabupaten Magelang. Terkenal dengan sebutan kota susu, Kabupaten Boyolali memiliki potensi wisata alam pegunungan, wisata air, dan wisata religi.

Waduk Cengklik merupakan salah satu obyek wisata air yang terkenal, karena letaknya yang sangat strategis berdekatan dengan Bandara internasional Adi Sumarmo, Embarkasi haji Donohudan dan Kota Surakarta yang mulai berkembang menjadi kota 
metropolis. Terletak di Desa Ngargorejo, Kecamatan Ngemplak $+20 \mathrm{~km}$ kearah timur laut dari pusat Kota Boyolali. Waduk seluas 300 ha ini dibangun pada jaman Belanda dengan tujuan untuk mengairi lahan persawahan seluas 1.578 ha. Disamping sebagai sumber air bagi Perusahaan Daerah Air Minum (PDAM) Kabupaten Boyolali dan dimanfaatkan sebagai tempat beternak ikan dengan sistim karamba oleh penduduk sekitar serta sebagai tempat berkembangbiaknya kumpulan burung bangau.Di masa sekarang ini Waduk Cengklik secara umum memiliki peran yang sangat penting bagi wilayah disekitarnya yaitu: 1) Sumber mata air permukaan dan air tanah; 2) Sumber irigasi bagi persawahan; 3) Ekosistem tempat tumbuh flora dan fauna; 4) Pengendali banjir wilayah Kota Solo; 5) Sumber mata pencaharian bagi penduduk. Fasilitas wisata yang ditawarkan adalah area pemancingan, karamba ikan dan area bersepeda.

Fungsi utama pembangunan Waduk Cengklik adalah untuk mengairi lahan persawahan. Sistem irigasi yang lancar menjadikan pertanian dapat berproduksi secara maksimal. Dalam setahun dapat panen padi sebanyak 3 kali. Disamping menghasilkan padi yang banyak, pertanian disini juga menyisakan jerami yang melimpah. Biasanya jerami ini dimanfaatkan sebagai pakan ternak (jerami segar), dibiarkan begitu saja sebagai pupuk atau dibakar.

Sedangkan fungsi waduk sebagai media keramba pemeliharaan ikan dan wisata air, sudah sangat menurun kapasitasnya karena keberadaan tumbuhan air enceng gondok (Euchornia Crassipes). Hal ini karena tanaman ini sangat cepat pertumbuhannya dan dapat menutup seluruh permukaan danau, sehingga kualitas air sebagai media perikanan dan juga keindahan waduk sangat menurun. Pemanfaatan enceng gondok dan limbah jerami padi sebagai pupuk dan pakan ternak, dapat memberi solusi pemecahan permasalahan tersebut.

\section{METODE}

Metode kegiatan yang dilaksanakan meliputi :

1. Pelaksanaan kegiatan ini dilakukan dengan cara bersama-sama dengan mitra dan perangkat desa untuk mengidentifikasi permasalahan, kebutuhan serta melakukan perencanaan sampai pelaksanaan kegiatan serta evaluasi.

2. Pelatihan pembuatan pupuk dan pakan dari enceng gondok dan jerami.

3. Praktek pembuatan pupuk dan pakan dari enceng gondok dan jerami.

Partisipasi mitra dalam pelaksanakan program IbM ini meliputi:

1. Penyediaan enceng gondok dan jerami sebagai pupuk dan pakan

2. Penyediaan tempat pembuatan kompos dan pakan

3. Penyediaan sumberdaya manusia sebagi subyek untuk dilatih berbagai kegiatan program ini.

\section{HASIL DAN PEMBAHASAN}

Hasil yang dicapai dalam kegiatan pengabdian ini adalah :

1. Telah dilakukan pelatihan pembuatan pupuk dan pakan dari enceng gondok dan jerami.

2. Telah dilakukan penyerahan bantuan alat pencacah enceng gondok dan jerami.

3. Telah dilakukan praktek pembuatan pupuk dan pakan dari enceng gondok dan jerami

4. Hasil pupuk organik dari enceng gondok

5. Hasil pakan silase dari jerami

\section{UCAPAN TERIMA KASIH}

Ucapan terima kasih disampaikan kepada Dirjen Pendidikan Dikti, yang telah mendanai kegiatan ini melalui Hibah Ipteks bagi Masyarakat Tahun Anggaran 2014. Ucapan terima kasih juha disampaikan kepada Kelompok Tani Mina Sejahtera dan Ngudi Makmuk yang telah bersedia menjadi mitra dan mendukung kegiatan IbM ini. 


\section{KESIMPULAN}

Pelaksanaan kegiatan ini dilakukan dengan cara bersama-sama dengan mitra dan perangkat desa untuk mengidentifikasi permasalahan, kebutuhan serta melakukan perencanaan sampai pelaksanaan kegiatan serta evaluasi melalui pelatihan pembuatan pupuk dan pakan dari enceng gondok dan jerami yang dilanjutkan praktek pembuatan pupuk dan pakan dari enceng gondok dan jerami

\section{DAFTAR PUSTAKA}

Mudjiman, Haris dan Ravik Karsidi. 1992. Penerapan Teknologi Tepat Guna dan Riset Aksi dalam Pengabdian Pada Masyarakat. Penataran Metodologi P2M, 24 Juni 1992. Surakarta:LP2M UNS.

Sugiarti, Rara.2000. Ekowisata.Laporan Penelitian. Surakarta: LPPM UNS. 


\section{Foto-foto Kegiatan Pengabdian}

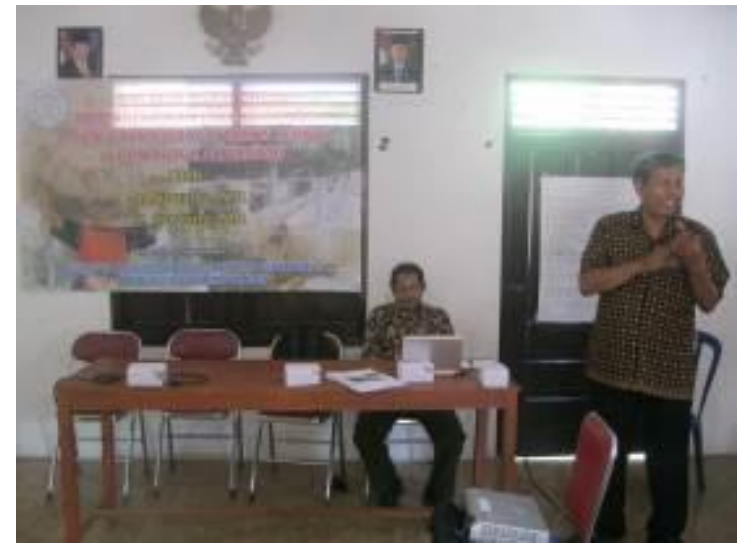

Penyuluhan Pembuatan Pakan Silase dari Jerami

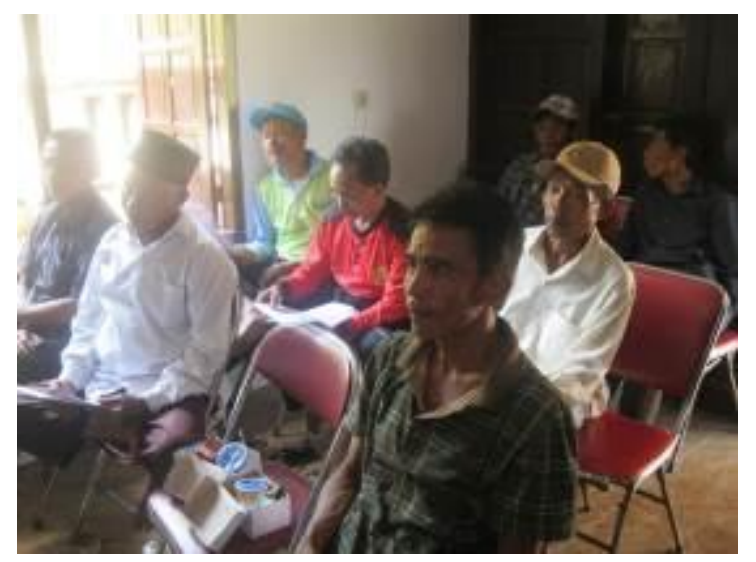

Peserta Penyuluhan Pembuatan Pakan Silase dari Jerami dan Pupuk Organik dari Enceng Gondong

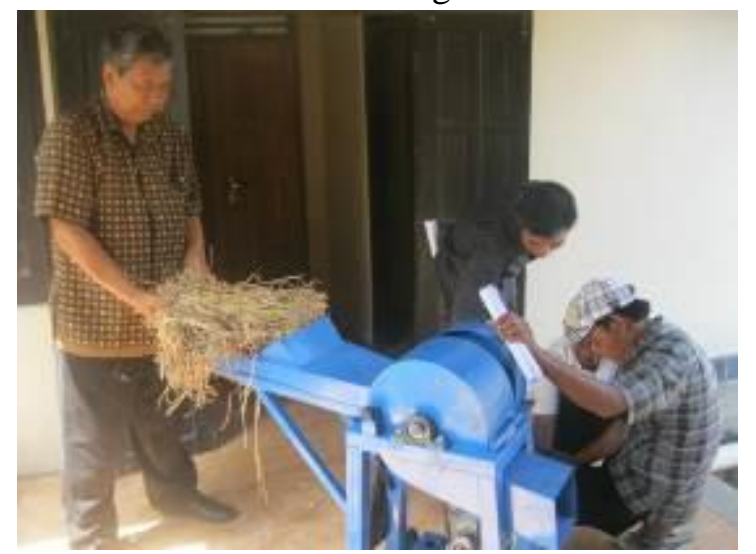

Praktek Pembuatan Pakan Silase dari Jerami

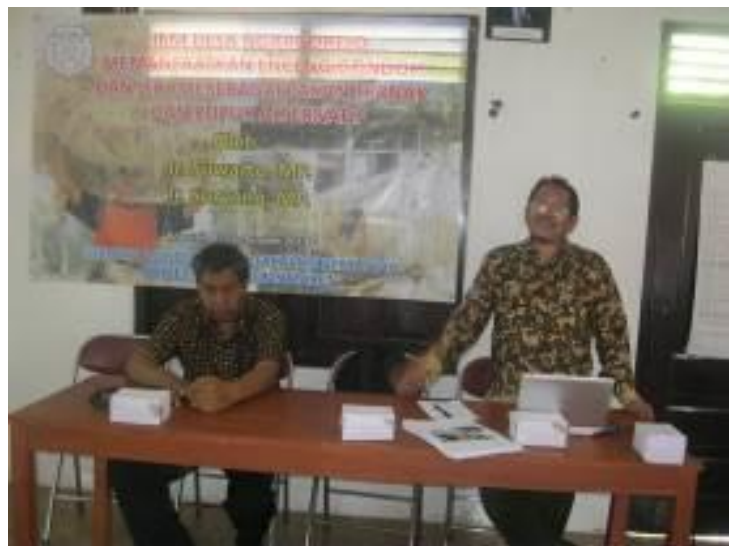

Penyuluhan Pembuatan Pupuk Organik dari Jerami

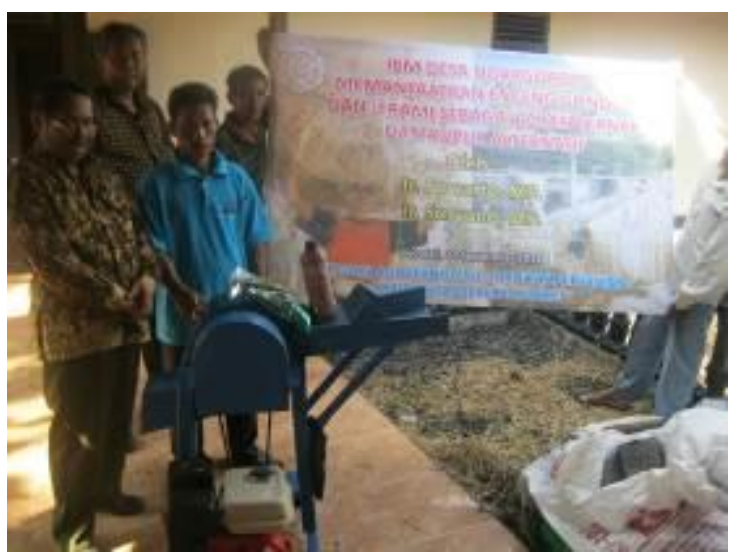

Penyerahan Bantuan Mesin Pencacah

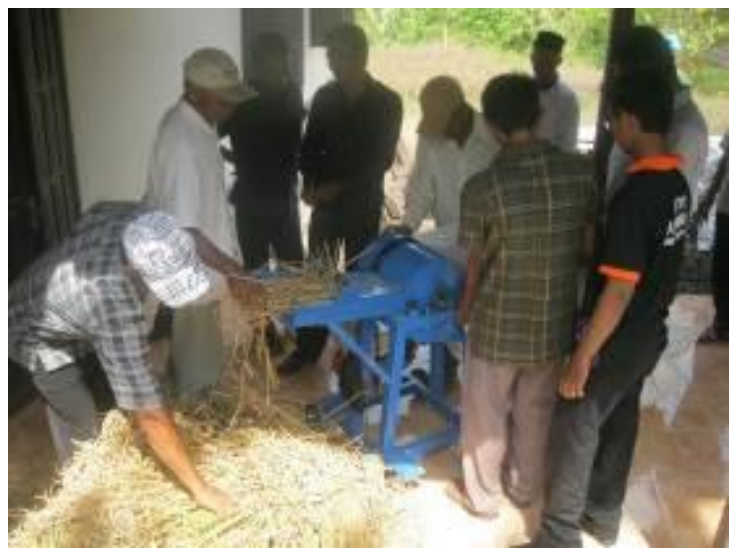

Praktek Pembuatan Pakan Silase dari Jerami 


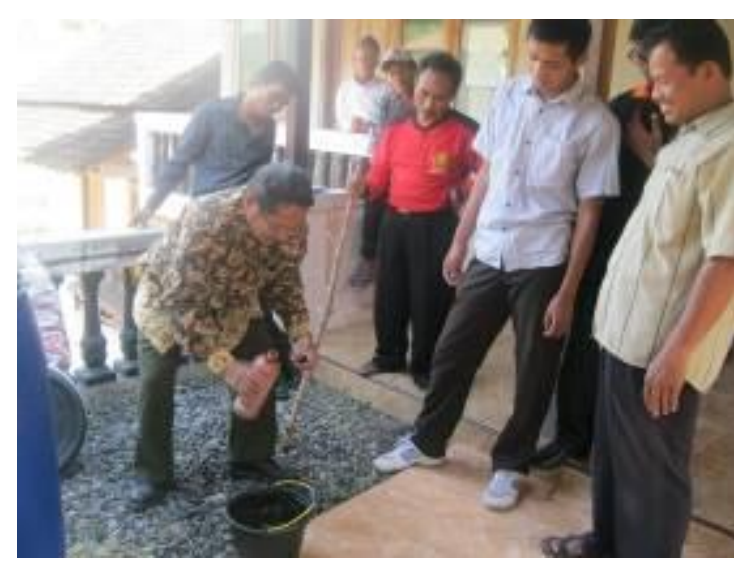

Praktek Pembuatan Pakan Silase dari Jerami (Pemberian EM4)

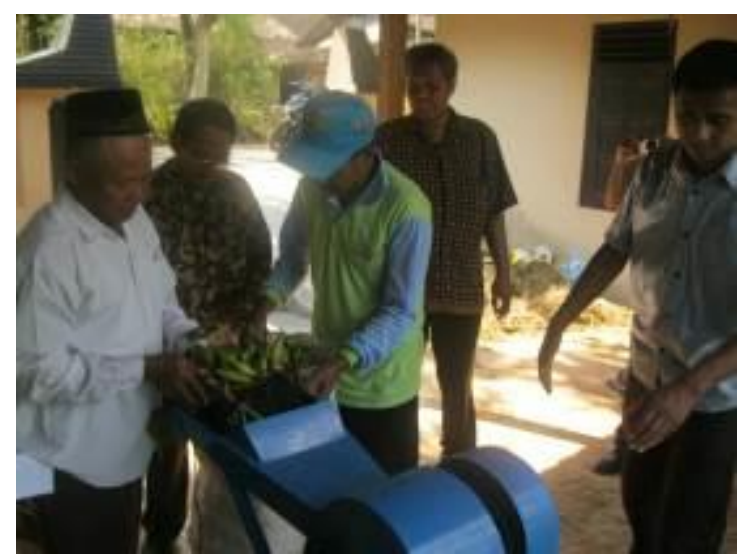

Pencacahan Enceng Gondok

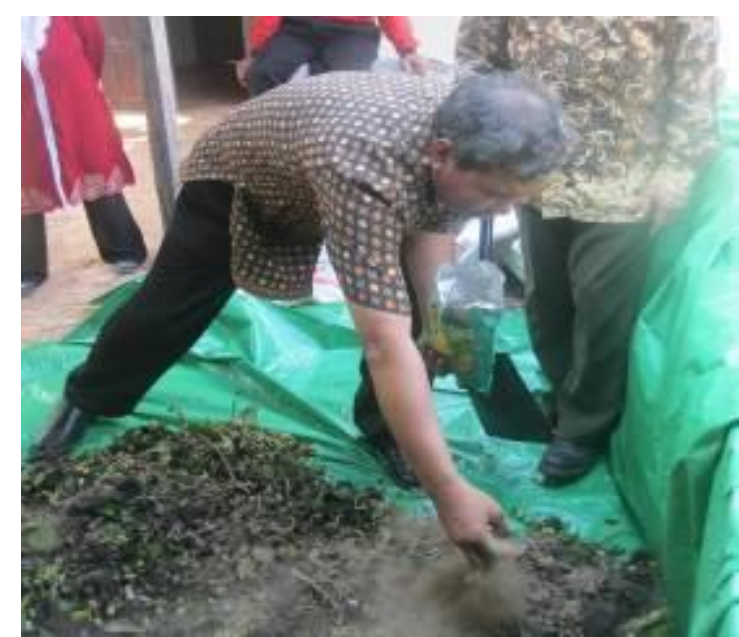

Penarburan Starbio Enceng Gondok

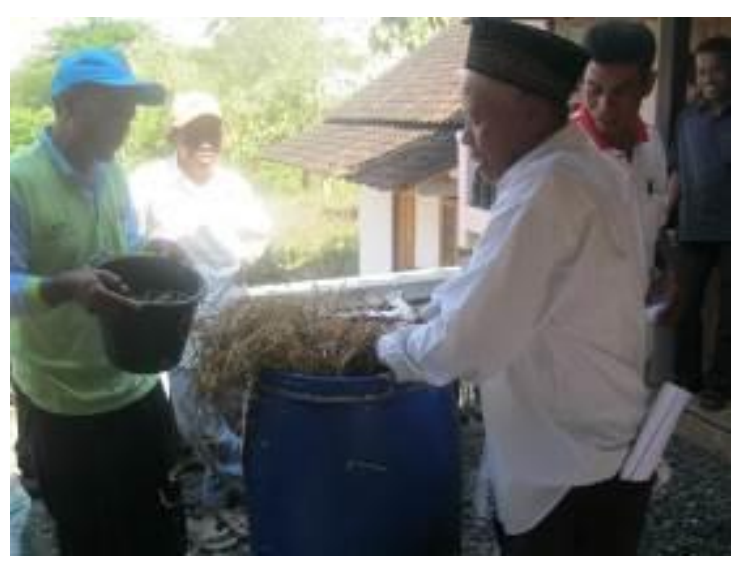

Praktek Pembuatan Pakan Silase dari Jerami (Pemberian EM4)

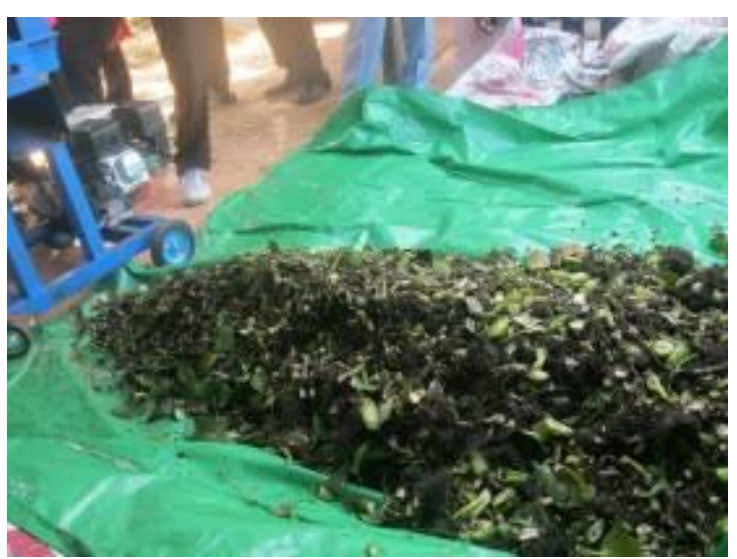

Enceng Gondok yang telah dicacah

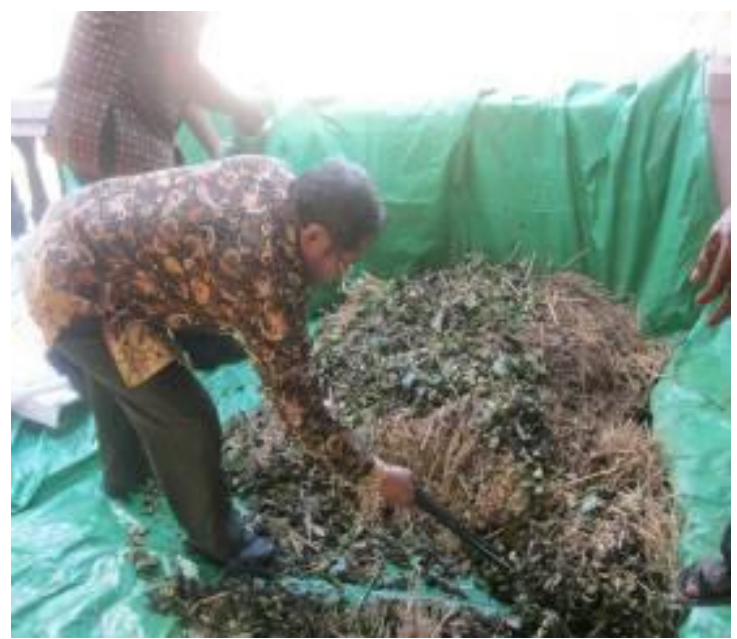

Enceng Gondok yang telah diberi Starbio diratakan 


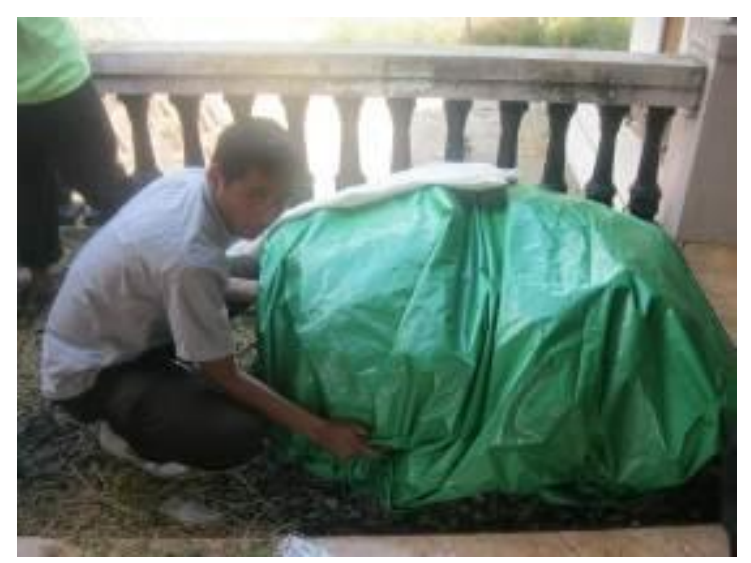

Pupuk Organik dari Enceng Gondok telah siap ditunggu

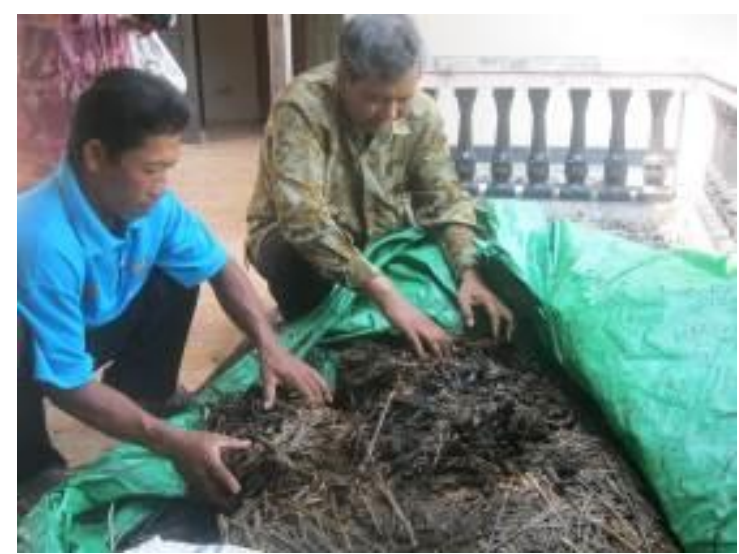

Hasil pupuk organik dari enceng gondok

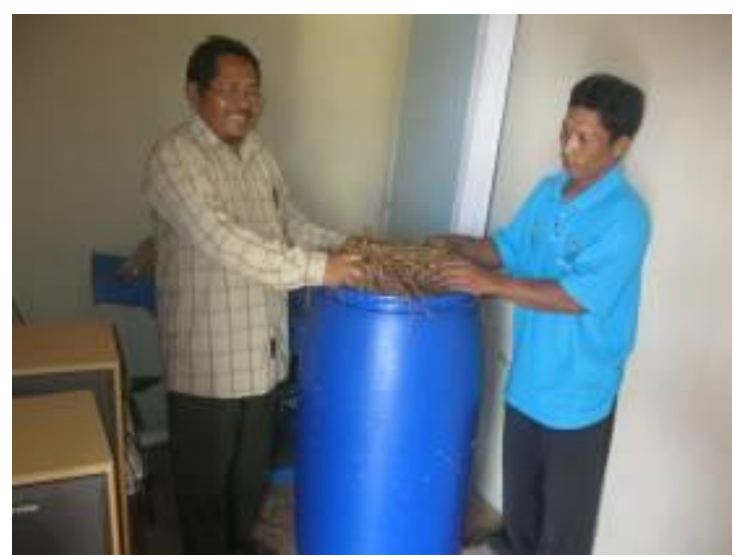

Hasil pakan silase dari jerami

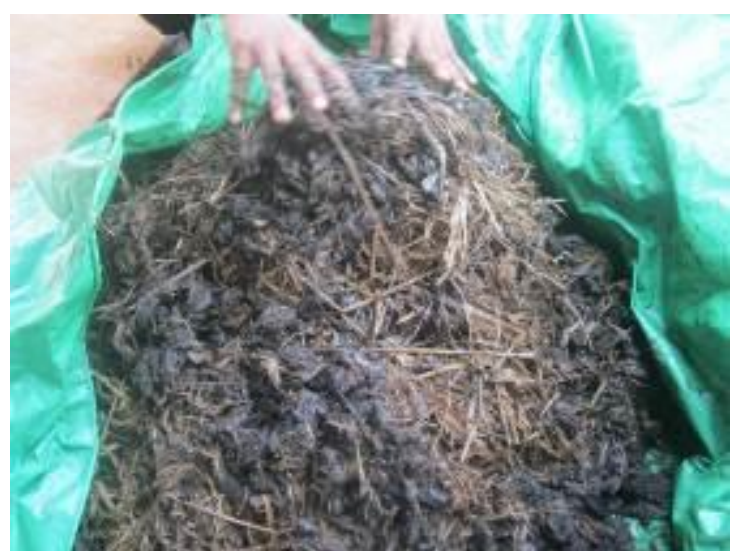

Hasil pupuk organik dari enceng gondok 